\title{
Benefits and Problems: Centralized Administration on College English Course in Chinese Higher Education Institutions
}

\author{
Zeng Zhen \\ ${ }^{1}$ College of International Studies, Southwest University, Chongqin, China \\ ${ }^{2}$ School of Foreign Studies, Guilin University of Electronic Technology, Guilin, Guangxi, China \\ Correspondence: Zeng Zhen, 82 Liuhe Road, Qixing District, Guilin, Guangxi, Postal Code: 541004, China. Tel: \\ 86-133-1773-0179. E-mail: joyzeng@163.com
}

Received: March 14, 2019

doi:10.5539/hes.v9n2p154

\begin{abstract}
It's arguable that more involvement of government with centralized policies causes less efficiency on education progresses. The article reviewed documents dedicated to or related to College English (CE), which have been released by Ministry of Education of People's Republic of China (MOE)and other institutions / organizations after 1949. Exploring CE's goal, assessment and national impacts, it's substantially analyzed the benefits and disadvantages of centralized governance conducted on $\mathrm{CE}$, and proposed an integral strategy potentially developed: conducting centralized administration while highlighting and enhancing diversity and individuality on $\mathrm{CE}$ for reaching the goal of $\mathrm{CE}$ in China higher education.
\end{abstract}

Keywords: centralized policies, benefits, problems, College English, higher education

\section{Introduction}

CE is a very section construct in Chinese higher education. It's reported that, in 2018, applicants for College Entrance Examination reached 9.75 million, 7.90 million of them enrolled into various universities and colleges across the country, 28.32 million undergraduates in total (Yu \& Zhang, 2019, Feb. 26). Confronting such huge population learners, CE mostly covers 2 academic years with 16 credits $(10 \%$ of total for being eligible of applying degree) which implying that there are at least 14 million students working on CE at same time (Department of Higher Education [DHE] of MOE,2007). In the Guides of College English Teaching, 2015 (the most recent centralized document on CE, brief as Guides 2015 below) again, "CE is the essential part in university foreign language education. It's a compulsory course for every non-English majors in Chinese tertiary institutions' (Wang, 2016). These statements establish and formulate a very populous and oversize CE. Such very eminent features have been arousing very peculiar concerns around $\mathrm{CE}$, and its efficient performance is foremost.

'Great investment, Low efficiency' is most critics because there is a great conflict between the eager demand of talents with English language proficiency and the low effect of CE functioning on this task in universities and colleges overall. Under such condition, this research proposed that the highly centralized governance conventions on CE play a low, even deficient role concerning the current situation of CE. The current context of learning and teaching foreign languages has been changing. It's analyzed that the diversified context of language teaching and learning need the adjustment of the conventions on $\mathrm{CE}$ on concerning the benefit and weakness of centralized governance, and proposed an integral strategy potentially supporting $\mathrm{CE}$ effectively functioning in China higher education.

\section{Researching Questions}

On this scale of teaching and learning, the centralize policies and regulation, as well as the promotion activities hardly cover and satisfy the demands of individual students, the teaching accounted on here because the faculty resource confronting this huge population in the course is short and tough, though these centralized efforts truly support CE in some aspects. There are 3 main questions discussed in the article:

What are the centralized policies working on CE of tertiary education in China?

What are the active and negative sides of the centralized governance performed in CE? 
How will these centralized policies be working in the future?

\section{Researching Methods}

The article is taking the advantage of the documents released by MOE on CE after the foundation of the People's Republic of China. By reviewing the goal, assessment and key event on CE, it will demonstrate that the centralized governance is playing a key role in $\mathrm{CE}$ development under the condition of teaching and learning English as a foreign language in China while the centralized policies is presenting an intendancy of deconstruction when confronting a new developmental era of advocating diversity and heterogeneity.

\section{Reviews on Centralized Administration on $\mathrm{CE}$}

\subsection{Centralized Governance Is Convention on Chinese Higher Education}

'Highly centralized governance' is a most typical feature of education after the foundation of the People's Republic of China. Since then, MOE has been being the highest institution charging issues related with education, though the name of this institution was occasionally changed a little during these years. In 1952, the State Council of China laid out the Adjustment Plan for Chinese Higher Education Institution (Deng, 2012, Nov. 11),centrally administering the tasks and goals of higher education institutions, including regulating students' enrollment process and controlling graduates' employment(Deng, 2012, Nov. 11). In 1958, the State Council released another document Requirements on Education, explicitly stating, "Education must be under the leadership of the Party (the executive party: Communist Party)" (Wang \& Meng, 2005). In 2010, MOE cooperating with other governmental institutes released the National Outline for Medium and Long term Educational Reform and Development 2010-2020 (MOE, National Development and Reform Commission [NDRC] and Ministry of Finance[MOF] of People's Republic of China, 2013). It's once again empowered centralized administration on education, "it's required that every party in education will fully implement the Party's policies in education..." (MOE, NDRC, MOF, 2013). As a whole, DHE (Department of Higher Education) of MOE fully administers issues around higher education institutions. CE, a compulsory course in Chinese higher education system, couldn't be exempted.

\subsection{National Professional Organizations and Committees under MOE as think tank on centrally administrating $C E$}

MOE centrally administers CE through varied documents and policies, and DHE of MOE is office of liberal Arts taking direct responsibilities of CE developments and conducts policies and activities of CE, like drawing up its goals, formulating its curriculum, assisting teaching and learning methods, mandating assessments, facilitating and improving physical lab and campus construction, updating technology and information system, organizing professional organizations and seminars for faculty development etc., which will be briefly illustrated next. In 1990, the MOE (then, called National Education Committee) established Foreign Language Teaching Advisory Board in Tertiary Education under MOE (briefly as the FLT Advisory Board below), a subdivision of Teaching Advisory Board in Tertiary Education under MOE, reorganized basing on National Textbook Edition Committee. The FLT Advisory Board is not an official department, but an organization under MOE, composed of experts and professors working on the field, assembled and commissioned by MOE (DHE of MOE,2005). The FLT Advisory Board has long been involved into all kinds of reforms on CE, conducting national excellent CE curriculum reform programs, inspecting and assessing CE teaching quality etc. Particularly, the FLT Advisory Board was authorized by MOE to design, revise and edit the national policies, like College English Teaching Syllabus 1999(revised)., the College English Course Teaching Requirements 2004(trial one) (brief as Requirement 2004(trial version) below), College English Course teaching Requirement 2007 (revised) (brief as Requirement 2007below), as well as the Guideline 2015, which are implemented among universities and colleges across the country with great efforts. The FLT advisory Board and the Testing Committee are two influential organizations working on issues related with CE, taking a high social status in the field under MOE, fulfilling their advisory functions very much. Besides, the members of the organizations are professionals with high reputations on CE, in linguistics, as well as in the education as a whole, who are eligible to advise and conduct the policy designed, revised, edited and launched.

Another key organization under leadership of MOE is National College English Test 4 and 6 Testing Committee (brief as Testing Committee below) under MOE. The members of Testing Committee are prestigious professors from key universities across the country commissioned by MOE. Testing Committee is charge of the national test-CET4 and 6, particularly on its design, reform and organization.

\subsection{Centralized Goal of CE}

As teaching English in China as a foreign language (EFL), all English courses in schooling of various levels are 
constructed and supported by centrally governmental offices. And the goal for $\mathrm{CE}$ has been experiencing changes with documents promoted by MOE. The very first goal on CE was initiated in Draft for 7 Years Foreign Language Plan 1964(brief as Draft 1964 below) (Central Committee of the Communist Party and the State Council of China, 1964) focusing on reading skill. This requirement was held up in later successive documents on CE: College English Teaching Syllabus 1985 (for Science and Engineering majors) (brief as the Syllabus 1985 below (Edition Panel for College English Teaching Syllabus, 1985). Entering 21 century, MOE launched a new run of national reforms on $\mathrm{CE}$ in line with the fast development of the state, furthering open up to the outside world policy, with releasing 3 important documents respectively in 10 years, from2002-2012. In the early 2004, Requirement 2004(trial version), was issued by MOE, adjusting the goal of CE towards "supporting students with integrally practical English language proficiency, typically mastering listening and speaking skills so that students are capable of exchange information in English effectively in their working and social communication on both writing and oral speaking." (DHE of MOE, 2004). In the Requirement 2007 (revised) issued by MOE, the goal of CE was confirmed explicitly on communicative capacity in English, stating as “...students are capable of effectively communicating in English in their future studying, working and social communication... which will satisfy the state's social development and international exchange demands as a whole."(DHE of MOE, 2007).

Today, Guides 2015 is nationally practiced in all Chinese higher institutions. It's drafted accordance with the significant governmental movement of the National Outline for Medium and long--term Education Reform and Development (2010-2010) (brief as the Outlined2010-20205 below)released by MOE, which depicted the talents needed as "talents with multiple skills, highly-skilled workers and pragmatic personnel", "concentrating on training highly qualified professionals and outstanding innovative talents". Specifically, in terms of English language teaching and learning, the Outline 2010-2020 expects to "practically improve university and college students' professional English level as well as their ability of conducting researching in English" (MOE,NDRC,\&MOF,2013). In line with the statement of the Outlined2010-20205, National Foreign Language Teaching Advisory Board (NFLTA) under MOE (Note 1) was authorized to draft and revise the Guides 2015. The core change in the Guides 2015 is constituted with a multiple (three levels to be exact) goals system instead of 'one goal for all' policy being exercised before (Wang, 2016), aiming to support diversified needs of students who are motivated differently in learning university-level English course, and integral English language proficiency is taken as the core for the goal in each level.

The progress of goals on CE from emphasizing reading skills to developing English language integral proficiency, has been going through a historical period catering for the country's developmental needs and demands. Around the centralized goal of CE, other aspects of CE are complied and constructed with the efforts for fulfillment of the centralized goal

\subsection{Centralized Assessment}

The centralized assessment is a part in centralized policies on CE. On assessment section, the Syllabus 1985 first time mandated a centralized English test as a main assessment for CE (Edition Panel for College English Teaching Syllabus, 1985). In 1987, the first national College English Test 4(CET4) was launched, and 1989, first College English Test 6 (CET6). These two tests were originally designed to test all non English majors, measuring their English language proficiency with a set of standardized measurement, and the results are only serving for promoting English teaching and learning efficiency afterwards (DHE of MOE, 1999; DHE of MOE, 2004; DHE of MOE, 2007; Wang, 2016 \& General Office of MOE, 2005). In Syllabus 1999, it's mandated that the CET 4 was an essential standardized assessment for all non English majors (DHE of MOE, 1999). In 1999, Spoken English Test (CET-SET) was first organized nationwide, with the purpose of improving oral skills and speaking proficiency in English, implying a intendancy for integral communicative proficiency which was defined in goal of next coming up centralized document: the Requirement 2004 (trial)(DHE of MOE, 2004a). The participants applying the oral tests shall firstly pass the written exams of CET 4 and CET 6 respectively with a referent score, which is, till know, an optional choice aiming to enhance Chinese English learners learning English in a higher level

In the first CET4, there were 100 thousands students taking part into the test (Yang, 2003), but today, possibly, more than 11 million students take the test in each testing season. It's exactly the NO.1 national examination, and the largest scale of exam for testing one subject worldwide.

\section{Centralized Promotion Programs on CE}

For promoting and effectively implementing centralized policies on CE top down, some organizations and committees under MOE organize and support lots of events and programs on motivating and invigorating CE in 
Chinese higher education institutions.

\subsection{National Teaching Competition and National Seminars for CE Faculties}

The $9^{\text {th }}$ (2018) 'SFLEP (Shanghai Foreign Language Education Press) Cup' National Foreign Language Teaching Contest (NFLTC) in tertiary education was co-organized by the FLT Advisory Board, Foreign language Literature Teaching Advisory Board in Tertiary Education under MOE (briefly as FLLT Advisory Board below), Foreign Language Teaching in Vocational Colleges Advisory Board under MOE and Shanghai Foreign Language Education Press (Note 2) (briefly as SFLEP below) (NFLTC, 2018, Dec.02). The contest started in 2010, originated for CE faculties only, once a year, with the explicit purpose of enhancing efficiency teaching of CE. The first contest got more than 10 thousand participants involved, covering all 31 provinces and thousands of universities and colleges through the country (NFLTC, 2010, Jul. 24). The winners of the contest will be awarded certifications on their excellent performances, first and second prize holders usually being offered with a free short term studying programs abroad. Besides, the victory will be counted into the contestant's teaching accountability in his/her university. The contest would be lively broadcast on mainstream medias. Most importantly, the winners' teaching videos will be consider a sample for all CE teachers because the judge panel of the contest usually is comprised of members of FLT Advisory Board, well-known English language educators and prestigious professors, who are key figures on giving advice or making policies of CE and commissioned by MOE. With supportive efforts of all these kinds, governmental enforcement as most, the contest now covers all foreign languages teaching in tertiary education nationwide.

Except the nationally centralized contest for CE faculty, there are national seminars organized and operated annually or regularly by official institutions or by socially influenced organizations with purpose for strengthening teaching professionalized and efficient, like Foreign Language Teaching and Research Press(FLTRP) (Note 3), a semi-official institution, which annually hold and organize National Training Programs for in-service EFL (English as Foreign Language) Teachers in Tertiary Education, in summer holiday. The training programs are created for all university faculties teaching English as foreign language. One significant program is Advanced Courses for Excellent Foreign Language Faculties at Young and Medium Age in Tertiary Education (brief as Advanced Courses below) (FLTRP, 2019, Feb. 26). The Advanced Courses started in 2006 was cooperated by National Research Centre for Foreign Language Education of Beijing Foreign Studies University and FLRP. In 2011, it became an only one program covering all foreign languages teaching and learning, an official program under MOE (FLTRP, 2019, Feb. 26).

All these events, seminars or training programs are held with dedicated goals: supporting CE teaching, improving the quality of $\mathrm{CE}$ teaching and enhancing CE configuration efficiency basing on the Requirements 2007 and the Guideline 2015that is a running on CE.

\subsection{Nationally Centralized English Contests for CE Students}

National English Competition for College Students (NECCS) is a populously national contest for inspecting university students' integral English language capacity, which is held with permit of Department of Higher Education of MOE, cooperated by the FLT Advisory Board and the Foreign Language Teaching and Research Association in Tertiary Education (brief as FLT RA) (Note 4). NECCS is a national contest for students enrolled in $\mathrm{CE}$, with the purpose of supporting the assessment of higher education institution conducted by MOE, fulfilling the goal of reforms in CE teaching as well as CET4 and 6 promulgated by MOE, and inspiring university student to learn English, promoting their English proficiency level (NECCS, 2019, Feb. 28). Till 2018, the contest, held once a year, was the $20^{\text {th }}$ contest of its own, covering thousands of domestic universities, and more than 1.2 million universities and colleges students involved each year. Winners of the contest finally are awarded a certification which is considered a eligibility when applying a higher academic program at home and applying a program of studying abroad sponsored by the state as well, even in competing a position in Chinese companies, etc. And the contest organization committee needs to report the event, especially its quantity (how many participants of this year are) and the quality (how good performance the contestant did) to relative departments of MOE, provincial Education Departments and regional FLT Advisory Board, after completion the contest procedure. Those most supportive organizations (universities or local organizations) who effectively promote the event would be praised and accounting into their accountability respectively. Besides, the awarded students and their tutors all are awarded again by their universities basing on individual university's assessment system.

Another prevailing national English contest for CE learners is 'FLTRP Cup (Note 5)' National English Speech Contest, started in 2002, now exclusively held by FLTRP, cooperating with the FLT Advisory Board and the English Language Teaching Advisory Board under MOE (briefly ELT Advisory Board). This contest is a 
semi-official event. Winners of the contest will be awarded attending a short-term cultural exchange program held abroad. All these efforts have made the company (FLTRP) an influential power in English education over the county, which greatly supports $\mathrm{CE}$ teaching and learning as a whole.

\section{Discussions}

\subsection{Benefit of Centralized Policies on CE}

\subsubsection{Fast Implementation on CE Reforms Cross the Country}

The centralized policies are benefit for a series of quick implements and responses reaching forth and back in a certain period crossing every corner of the country, improving the teaching and condition in general on considering education equity. In the form starting in 2002, the Requirements 2004 (trial version) was released and then revised with the Requirement 2007, which highlighted the goal of oral speaking and writing skills, especially the integral English language proficiency in communication. Basing on the centralized goal, establishment of technology assistant facility for CE stated in the Requirement 2007 had been implemented quickly on campus, which required reform of $\mathrm{CE}$ teaching mode, transforming 'teacher center' the educational conception to 'students center', supporting student's communicative skills with informational technology. This is a pragmatic example on the case: centralized reform policy issued and promoted by MOE. For ensuring the success of the Requirement 2007, MOE commissioned Higher Education Press, Tusinghua University Press, FLTLP, and Shanghai Foreign Language Education, 4 main players in language productions and publishing in the state, with every effort in a few months to develop 4 sets of teaching and learning soft-wares applicably used through computers and networks, which were officially examined and verified by expert panel from MOE soon (Wu, then, vice Ministry of MOE, 2004). These network resources became fundamental components in another run national reform on CE initiated in 2002. For testifying the efficiency of the software and the teaching mode accordance with it in order to ensure the reform successfully moving on and producing maximum positive effect on CE course nationwide, MOE launched a project for experiment of those newly computer- assistant system as well as new teaching and learning mode on $\mathrm{CE}$ among screened universities and colleges conducting, which has been lasting for years, 3 continuously runs of experiments till now so far. The screened universities and colleges in each run would be officially released by MOE. In first run of this kind, 188 universities and colleges from 288 applicants was listed which are state prestigious ones, and it's stated that MOE financially supports experimental universities with 100 thousands RMB each for purchasing the dedicated software and textbooks, as well as paying for application training on operating software (DHE of MOE, 2004b).

Presently, after this continuous effort in years, there have been near 10 million on campus students learning English through Computer and Network Teaching Mode underlying the goal set up in the Requirement 2007, enjoying the benefit of centralized policies on CE mandated by MOE.

6.1.2 Concurrent Reforms Around Higher Education Released by MOE Effectively Consistent to Each Other Substantially Supporting the Goal of CE and All Its Aspects As Well

MOE is the highest administration institution of People's Republic of China, governing state educational issues. It's the only one institution to launch policies working on China education. The highly centralized power of MOE results, in some aspects, in a compromised and supportive accordance between its various policies.

In the Requirement 2004, the centralized goal of CE is striving to integral English language proficiency in communication, highlighting oral and speaking skills. Before long, National CET4 and 6 reform in 2005 was launched by MOE, initiating a new testing mode-On-line Testing Marking which consists of a test pool with hundreds and thousands of tests for CET4 and 6,70\% items dedicated for listening proficiency, presenting the requirement of the goal defined in the Requirement 2004(DHE of MOE, 2004a). The testing innovation was supported by a significant national Undergraduate Teaching Quality and Teaching Reform Program in Tertiary Education (Note 6) 2007(brief as Reform Program) (Ministry of Education and Ministry of Finance[MOE\& MOF], 2007) promulgated by MOE one year later. This movement detailed CE with the establishment of online testing system for national CET, aiming to improve English language proficiency among 60\% undergraduates in tertiary education, particularly oral speaking and listening skills improvement in a 4-year term (MOE \& MOF, 2007). This statement of the Reform Program 2007was substantially impetus to reach the centralized goal of CE set up in the Requirement 2004 and the Requirement 2007 afterward. After the Reform Program 2007 released, the online testing system for CET4 and 6 went through 2 times of trials starting in 2008, participated totally by 5000 students each time for CET 4, covering 50 universities and colleges. The achievement from the online testing system was verified through the general performance of student candidates in CET4 and 6, in which the passing rate of CET4 comparatively increased 14 percentage points according to the report from the Testing Committee (DHE of MOE, 2009). 
6.1.3 Centralized Policy is Easy to Balance the Resource Allocation across the Country, Supporting the Remote Areas to Get Its CE Developed, Striving for Equal Development in CE across the Country

Due to the historical reasons, the development of Chinese universities and colleges are greatly different on scales of both academics and social impact. Its' observed that most prestigious universities and colleges have long been enjoying most privileged policies and financial supports. From the educational budget 2016 released by 73 higher education institutions, it's remarkably presenting the huge gaps existing among Chinese universities and colleges. The first three universities on the list with high budget of 2016 were Tsinghua University, Zhejiang University and Beijing University, each of which proposed budget of more than 10 billion RMB. The rest 70 universities and colleges are all directly administered by MOE and prestigious ones in the country, but the budget gap between the very first third projects to the last one was astonishing, discrepancy of 17.9 billion RMB (Sha, 2016, May,13), let alone other ordinary universities, around 2000 not on the list. For balancing the situation, the Chinese government launched and will launch many reforms and programs through centralized policies, hopefully improving it in certain scale. The effective case here is effective implementation of the Plan 2012-2020 released cooperatively by MOE, Ministry of Finance and National Development and Reform Commission (Note 7). Minister of Department of Higher Education said, "There are 65.5\% university and college students studying on campus located in the mid-west area in china, where the academic and scales level of the higher education institutions are largely left behind, compared with that of in east area of the country. The lower quality restrains their development. For strengthening in infrastructure as a whole, development of higher education institutions in the mid-west area is highlighted as an appealing task," when interviewed Zhang, Daliang, head of MOE on the Plan 2012-2020 (DHE of MOE, 2013, May, 22). This is an unprecedented program of establishment and improvement towards low level universities and colleges in mid-west area of the country, pursuing the goal of optimizing resources disposition in the country, supporting establishment of high level regional universities and colleges to impetus local economic development. With the Plan 2012-2020, there will be 10 billion RMB investing mid-west area to support establishment of about 100 high level universities during the period (DHE of MOE, 2013, May, 22). It's a huge step on supporting the less developed university and college as a whole, CE definitely included.

Around the centralized goal of $\mathrm{CE}$, other policies are implemented to provide equal opportunities for improving efficiency, especially policies on CE faculties' professional development. On the previous section of stating the national centralized contest for $\mathrm{CE}$ faculty, it's showed the benefit of the national events for enhancing teaching quality of $\mathrm{CE}$ and also a equal case with centralized governance, which implied there are equal opportunities offered for all faculties to strengthen individual development, benefiting them with equal chances of promotion on their positions as well as their professional status as a whole. Another more popular project for equally application of teaching development is programs organized or launched by the China Scholarship Council (CSC) (Note 8). For example, CSC releases, each year, a short term oversea visiting programs for English teachers in tertiary education in west area, cooperated with University of Aberdeen of Britain. It's a specialized program, aiming directly to improve the quality of university and college English teachers working in west area, 2 runs, 35 candidates each in one year (China Scholarship Council, 2016). This is just a small program of the special programs /regional cooperatively specialized program for training teacher talents in the west area. Actually, many more other programs applicable for CE faculties implemented and organized by CSC, like state sponsored programs for Studying Oversea For Advanced Research Scholars, Visiting Scholars, Pos-Doctors; programs for excellent young faculties studying abroad, exchanged programs, as well was programs co-sponsored by local governments etc, strongly and equally support the improvement of CE teachers' teaching level as well as student's English learning in tertiary education. All these programs are open for all CE faculties.

6.1.4 Centralized Policies Widely Support Exchanges and Communication between Universities and Colleges with United Requirements and Standards

National CET 4 and CET 6 are state tests, providing a standard for assessing English language level of learners attending CE, though are widely arguable and questionable. Generally speaking, the centralized tests are greatly supporting the exchanges on CE issues in different universities and colleges basing on its uniqueness in the field. According to the function defined in the syllabus 1985 and statements in later documents for CE, CET4 and CET6 are supporting the CE teaching and learning, assessing and measuring the CE teaching efficiency and support the fulfillment of the goad of CE in higher education as a whole. In this aspect, as the only one measurement on $\mathrm{CE}, \mathrm{CE}$ faculties can practicably learn from each other through comparison on teaching performance and test results in certain period, which will be beneficial for enhancing and improving the teaching quality as well as students' learning ability. On another aspect, the results of the national tests will explicitly explain and demonstrate the weakness and achievement of CE in certain period, which will effectively support 
the design and reform policies and programs in next run.

Besides, with CE increasingly social value----a key competitive ability in employment market, particular in competing positions directly requiring English proficiency, the centralized tests, in fact, spread the conception of importance of English proficiency across the country, as well as the goal of CE and its measurement effectively, substantially supporting English language teaching and learning as well as English proficiency level. It's hopefully to establish more English language speaking communities in future.

\subsection{Problems of Centralized Governance on CE}

As stated before, English is a foreign language in China, English language is not a social language and there is no much English community exiting in China in large extend. Under the setting on Chinese teaching and learning, English language resource is essence of defining English development in China----constraining while supporting the English language teaching as a foreign language because there are so much gaps, geographically, politically, culturally existing across the country. In terms of diversity and homogeneity, there are concerns being aroused on $\mathrm{CE}$ with its centralized policies.

\subsubsection{The Challenge of Diversified Developing Level in English Language Teaching and Learning}

It's a common sense that, highly developed areas hold much more resources and opportunities to promote its English language teaching and learning, like universities and colleges located at east costal area, which has long been taking regional advantage of well founded social status enjoyed by English language teaching and learning, because the east coastal areas have historically developed its conception on communicating to the western countries. Besides, these universities and colleges are basically encouraged on English languages development in the area with many foreign owned companies or programs run over there, establishing community of English language speaking required. This well constructed setting for English learning contributes a lot on higher level development on $\mathrm{CE}$ in these areas. Motivations resulting from the prosperously economic exchanges with English speaking counties, produce impetus to university students English learning and English language proficiency in a higher level among other Chinese tertiary institutions without doubt, particularly when compared those in west part of the country where are conventionally shortage of the resources and opportunities for English language teaching and learning. For those educated in metropolitan and developed area, English is part of their life, but a thing only learned from textbooks or videos for those living in developing areas, which leads to a concern of inequity of $\mathrm{CE}$ if centralized policies on $\mathrm{CE}$ are going through equally every corner of the country. This challenge of unbalanced English resource disposition in different areas increasingly causes various discrepancies which worsening the challenge, even forming a bigger challenge or more challenges on educational equity. It's a case that Tsinghua University Assessment on CE exempts from the centralized testing system, an example for the point here. As a most prestigious university of the state, Tsinghua University launched its own assessment on CE----Tsinghua English Proficiency Test (TEPT), which was revised in 2011 for further reducing the low efficiency of CET 4 and CET 6 on inspecting Tsinghua students English language proficiency(Anonymous, 2012,Sep.16). The revision of TEPT 2011 is aiming to promote English Academic Proficiency (EAP) teaching and learning on CE, supporting students' academic studying. Students of Tsinghua University will be awarded Certification for passing TEPT, and the test is accredited by MOE (Foreign Language Testing Panel, 2012). This unique Tsinghua University assessment exempts the university from the National CET4 and 6 while many thousands of universities and colleges located in different rejoins of the state are struggle to reach the centralized CET4 and 6 without option, let alone students own demands. This really arouses new inequity in $\mathrm{CE}$ as well as argument around diversity and homogeneity.

The case clearly presents the fact that the nationally centralized CET 4 and 6 are unable to serve every on-campus students enrolled in CE, at least unable to those with higher level English language proficiency students, and not for those lower developed neither. Actually, the CE is open to all non English major students, but with same goal, same textbooks, same teaching mode, and assessed by same CET4 and6, completely ignoring the diversified background of the students enrolled in the course at very beginning. It's Tsinghua University, a No.1 prestigious university that is able to create its own test aiming to supporting its own students' demands with permit of MOE. To those who are still short of English learning resources, it's a dream of creation its own test for its students.

6.2.2 Centralized National CET4 and 6 Causes Organized Cheating Over the Nation, Challenging the Diversity and Homogeneity, and Equity as a Whole

The most arguments and critics on CE are related with the National CET4 and CET 6, the largest scale national test ever, like stated above. It's well recognized that the tests are more than a measurement on campus, though the Syllabus 1985, explicitly stating that students completing CE will be tested with a united test, didn't mandate 
the results of the test a prerequisite for graduation as well as being awarded a degree. However, as the only standard English test, verifying students English language capability, nearly all universities and colleges account the score of the tests into granting degree certification or not, though no any official document say so. Additionally, as the tests are accredited by MOE, the result--the CET4 and 6 certification (before 2005) or a score transcript (released after 2005) released by the testing Committee under MOE, it's recognized as one standard used by employers, who believe the certificated candidates holding a higher mark of CET4 or 6 test are more capable of the position offered, no matter English necessary for the position or not. Additionally, such social effect creates radical competition among students. Some students with more language learning resources (more chances of visiting English language speaking countries, or more engaging into English language programs etc.) would ready well for such tests with high marks, taking a privilege over the language screening on job hunting. But for large amount of students, CET4 and 6 are their nightmares. For the degree, for hunting job, some of them turned to cheat on the tests. With factors involved, the nationally centralized tests become a profitable target to each party (students, employers, profit purchasers, opportunists...), inside and outside of the campus. Because it's a largest scale of tests nationwide, the cheating is, no-doubt, astonishing. The top-down centralized policies quickly response on the issue, working against the frauds and to protect equity of all test participants. Firstly, in 2004, MOE laid out Regulations on National Examinations in Education, an administrative document, explicitly stating that those who cheat would be expelled from school (MOE, 2004, May, 19). Secondly, the Testing Committee has continuously launched several reforms on the testing forms, the National CET4 and 6 Reform 2005 a biggest step on reforming CET4 and CET6 tests, changing the form of releasing results of CET4 and CET 6 with transcript instead of delivery of CET4 and 6 certification, emphasizing its function of serving the improvement of CE teaching in higher education (General Office of MOE,2005), in order to stop using the certification as one standard for granting degree certification that is most impetus for students cheating the tests. Besides, this Testing Reform 2005 proposed establishment and implementation of On-line Testing Marking system through computers which will randomly offer different type of testing items and contents, aiming to decrease the possibilities of cheating (General Office of MOE,2005). Thirdly, in 2012, the Testing Committee started to adapt 'multiple test and variety content' design into the national CET 4 and CET 6 (Anonymous, 2012,Dec. 12) in order to use different testing paper with different configuration of content to prevent the exacerbated cheating year after year. Today, with launch of the Legislation Amendment (9) of Criminal Law on November 1st, 2015, mandating that organized cheating in national tests is a crime, the maximum punishment reaching 7 years imprisonment(The General Offices of the NPC Standing Committee, 2015), the National CET4 and CET 6, as No.1 national test, are not exempted from the law. This is the highest level and severe rules against cheating on test in China. And several universities quickly reacted to the legislation. Before the very first national CET4 and CET 6 after the legislation implementation, the Academic Affair Office of City College of Wuhan University of Technology(issued a letter to all tests participants, stated explicitly that the college will severely punish those conducting fraud behaviors in the CET4 and CET 6 with disqualification of degree certification. This letter got quickly responsive on networks and criticized as 'most brutal regulation for cheating in CET4 and CET 6' (Anonymous, 2015,Dec.12). There hasn't any report on its effect, but the negative views on these centralized English tests are not stopping.

There is no evidence for the national CET4 and 6 going awfully useless, but there is a clear fact that the cheating on tests would not stop till the problem of diversify and homogeneity of English teaching and learning across the country is reasonably noticed and dealt with.. Due to its unique status for verification of English language proficiency that produce incredibly social impact-centralized standard in the field which is accepted in employment market and a qualification relating with degree rewarded in the most cases nationwide, there is obviously difficult to stop the fraud behaviors in the tests with efforts which even escalating to legislative level with this 'one for all' testing policy. Fortunately, a kind of agreements has been reached, with the efforts of all kinds, that diversity is highlighted in the Guideline 2015 that first time described a multi-level goal system, considering students' diversified motivation and demands on learning CE a centre of the policy (Wang, 2016). Besides, the CSE is issued top-down, which is considered a potential solution, another centralized policy working on CE, hopefully.

\section{Results}

In China, CE is a course teaching and learning English as Foreign language (EFL), where there is no, generally speaking, prevailing English speaking communities beyond campus. This defines the foundation of policy making and implementation across the country, where CE is totally a policy-based reliance as a, in big picture of $\mathrm{CE}$ of the country, most largest scale of course constructed in higher education system in China, beneficially supportive centralized policies, on the course goal, testing system, dedicated competition, etc. in general. 
However, severe developmental gap between regions in the country, which directly impact on educational level and demand on students English language proficiency level as well as their motivations, appeals diversified measures and policies considering the heterogeneity.

\subsection{Integrated Centralization and Diversification}

Integration would be the trend for policies of $\mathrm{CE}$ in future. Looking through the documents on CE released since the very innovative CE reform starting 2002, it's presented the intendancy of being optional and diversified: firstly, the name of the documents - the Syllabus 1999, the Requirement 2004(trial) and the Requirements 2007(revised), till today, the Guidelines 2015, used changed from Requirement to Guideline, implied a more optional and less mandated attitude of the centralized policies on concerning diversify. Second, the multiple level curriculum system has been gradually promoted in these centralized documents. It's read in the Requirement 2004(trial), and the Requirement 2007that there 3 teaching levels of CE: general requirement, medium level requirement, and higher level requirement (DHE of MOE, 2004a; DHE of MOE, 2007), which agreed that there are diversified students with different English language proficiency level enrolled in CE, so there should be a curriculum system, offering different level CE teaching and learning. Last but not the least, this statement on multilevel curriculum system is revised with a multi-goal system in the Guide 2015, supporting 'universities and colleges to start their own CE teaching and learning, basing on pragmatic situation of their own, with a level of teaching goal in the goal system... which is beneficial to conduct CE teaching and learning and satisfy diversified demand of the university, each faculties on the campus as well as students enrolled in the course'(Wang, 2016).

\subsection{Establishment of Alternative Professional Standard for Screening Talents with English Language Proficiency}

As far as it's concerned, the spotlight on $\mathrm{CE}$ is mostly related to its unexpected function practicing in labor market. One solution is coming out with National Advanced Forum of Foreign Language Education in Higher Education Institutions 2016 held in Beijing, China in April, 2016, which was organized by the Foreign Language and literature Advisory Board under MOE, the FLT Advisory Board and Beijing Foreign Studies University. In the conference, China Language Assessment (CLA), a researching institution of Beijing Foreign Studies University, presented a brand new program-English Test for International Communication (ETIC). It'd help candidate applicants for competing post in employment market and for in-service employees pursuing promoting in their working place. The function and the goal of the test is diverse to 'on-going assessment of TEFOL, GRE, CET 4 and CET 6 completely' (Guo, 2016, Sep. 28). The design and establishment of ETIC is based on the state's requirement for diversified talents with high level English Language Proficiency under the state's economic blueprint launched for the coming up years. Accordingly, the assessment of CE definitely will getting back to its function, originally up in very first centralized document the Syllabus 1985, 'to inspect and support the CE teaching efficiency' as well as explicitly stated in the Testing Reform 2005 with goal to 'support and improve CE teaching efficiency'(General Office of Ministry of Education, 2005).

\section{Conclusion}

Evidently basing from above illustration, centralized policies are readily to spread over the country overnight without any obstructs or questions, and any delay for implementation, producing intense interactions and impacts on CE: centralized goal guiding every faculty of the CE department; centralized assessment offering a standard to inspect and monitor CE teaching and learning as a whole, benefit on exchange of effective teaching and learning mode as well as of cooperation programs between CE faculties in different university and colleges; centralized organizations of $\mathrm{CE}$ and centralized contests and competition for $\mathrm{CE}$ faculties an students supporting and enhancing CE status in the country, a non- English speaking community, as well as increasing English language proficiency level nationwide. On the other side of a coin with two sides, united and centralized policies produce problem too, inequity or cheating, restrain the effectiveness and development of CE, less effectively training talents with high English language proficiency demanded by the state in its economic and political road-map. No matter which side is preferred by a party concerned, being consistent with the benefit of centralized governance on $\mathrm{CE}$ in tertiary education, there is a need and intendancy for a integral power-implementation of top-down policies while highlights diversified consideration respectively. Under the condition of teaching and learning English as a foreign language in China, it's necessary to mandate baseline and rout and goal of CE in the macro level, benefiting from centralized policy, and the universities and colleges in different areas conduct its own CE plans and activities basing on the locally actual demands and resource around $\mathrm{CE}$, displaying its diversity and heterogeneity.

\section{Acknowledgements}

This researching is a part of an on-going funding researching program on Teacher Education Preparation which is co-worked with an Professor Wen, xu, Southwest University, Chongqin, China, and supported by the fund 
form Gulin University of Electronic Technology, Guilin, China. Greatly appreciations go to all friends concerns.

\section{Reference}

Anonymous (2012, Dec. 12). Reform the national CET4 and 6 for against cheating. Retrieved from http://www.gov.cn/jrzg/2012-12/19/content_2293877.htm

Anonymous (2012, Sep.16). Tsinghua University English Proficiency Test Reform (2012), firstly Conducted In December This year. Retrieved from http://page.renren.com/600806598/channel-noteshow-871418401?pid=600806598

Anonymous (2015, Dec.12). The severe punishment on cheating in CET4 and 6 launched by a higher education institution in Wuhan (discussion). Retrieved from http://hb.sina.com.cn/news/w/2015-12-19/detail-ifxmttme5836052.shtml

Central Committee of the Communist Party and the State Council of China (1964) (Sep. 06, 2012). On two documents related to 7 Years Plan of Foreign Language Education. Retrieved from http://guoqing.china.com.cn/2012-09/06/content_0.htm

China Scholarship Council (2016). A short term oversea visiting programs for English teachers of tertiary education in foreign countries. Retrieved from CSC portal. Retrieved from http://www.csc.edu.cn/article/575

Deng, J. L. (2012, Nov. 11). Reviewing the Adjustment Plan for Chinese Higher Education Institutions in 1952. Retrieved from http://www.aisixiang.com/data/59061.html

DHE of MOE (2004a). College English Course Teaching Requirements 2004( trial), in document of No.1 (2004). Retrieved from MOE portal. Retrieved from http://www.moe.edu.cn/publicfiles/business/htmlfiles/moe/moe_734/200408/729.html

DHE of MOE (2004b). Announcement On Conducting Experimental Trails on College English Teaching. In document of No.21. Retrieved from http://www.moe.gov.cn/s78/A08/s4532/201001/t20100129_93342.html

DHE of MOE (2005). Announcement on recommending new terms of members for Teaching Advisory Board in Tertiary Education under MOE. Retrieved from http://www.moe.gov.cn/srcsite/A08/s7056/200504/t20050418_124825.html

DHE of MOE (1999). College English Teaching Syllabus 1999(revised). Higher Education Press and Shanghai Foreign Language Education Press, (2nd Eds.).

DHE of MOE (2007). College English Course teaching Requirement 2007 (revised). Foreign Language Teaching and Research Press.

Edition Panel for College English Teaching Syllabus (1985). College English Teaching Syllabus (for science and Engineering majors). Higher Education Press.

FLTRP (2019, Feb.26). National College students competitions on English speaking, reading and writing. Retrieved from http://uchallenge.unipus.cn

Foreign Language Testing Panel (2012). Tsinghua University English Proficiency Test (TEPT) (2 $2^{\text {nd }}$ eds.).Tsinghua University Press.

General Office of MOE (2005). An Announcement on Reforming National CET 4 and 6 (trial) No.1[2005] from General Office of MOE. Retrieved from http://old.moe.gov.cn/publicfiles/business/htmlfiles/moe/moe_991/201011/110833.html

Guo, W. (2016, Sep.28). National advanced forum on foreign language education reform and development in tertiary education. Retrieved from http://news.bfsu.edu.cn/archives/254357

Ministry of Education and Ministry of Finance (2007). Undergraduate Teaching Quality and Teaching Reform Program in Tertiary Education under Cooperation of MOE and Ministry of Finance of People's Republic of China. DHE [2007]. Retrieved from http://www.moe.gov.cn/s78/A08/moe_734/201001/t20100129_20038.html

Ministry of Education and National Language Commission (2018). China's Standards of English Language Ability. Retrieved from

http://www.moe.gov.cn/jyb_xwfb/gzdt_gzdt/s5987/201804/t20180416_333331.html

MOE (2004, May,19). Regulation on Violation in National Education Examination,( the No.18 of MOE). 
Retrieved from http://old.moe.gov.cn/publicfiles/business/htmlfiles/moe/moe_621/200409/3173.html

MOE, NDRC \& MOF (2013). An Announcement on launching Revitalization Plan of Tertiary Education in Mid-West Area of China (2012-2020), in document of No.2(2013). Retrieved from http://www.moe.edu.cn/publicfiles/business/htmlfiles/moe/s7056/201303/148468.html

National Development and Reform Commission and MOE (2015). Announcement on National Enrollment Plan of Higher Education, Retrieved from http://old.moe.gov.cn/publicfiles/business/htmlfiles/moe/s7050/201504/186363.html

NECCS (2019, Feb. 28). National English Competition for College Students (NECCS). Retrieved from http://www.chinaneccs.org/

NFLTC (2010, Jul. 24). First SFLEP Cup National Foreign Language Teaching Contest ended successfully. Retrieved from http://nfltc.sflep.com/2010/review/shoujiehuigu/2010/0624/195.html

NFLTC (2018, Dec.02). The 9th SFLEP Cup National Foreign Language Teaching Contest ended successfully. Retrieved from http://nfltc.sflep.com/2010/news/2018/1202/844.html

Office of National Medium and Long Term Educational Reform and Development (2010). National Medium and Long term Educational Reform and Development Outline 2010-2020. Retrieved from http://old.moe.gov.cn/publicfiles/business/htmlfiles/moe/info_list/201407/xxgk_171904.html

Sha, L. (2016, May, 13). Budget of 73 universities and colleges directly under MOE, Discrepancy Of 17.9 Billion $R M B$ between TsingHua university and last university on the list. Retrieved from http://news.ifeng.com/a/20160513/48761210_0.shtml

The General Offices of the NPC Standing Committee (2015). The Legislation Amendment of Criminal Law (9). Retrieved from NPC (the National People's Congress of the People's Republic of China) portal. Retrieved from http://www.npc.gov.cn/npc/xinwen/2015-08/31/content_1945587.htm

Wang, M. Y., \& Meng, X. (2005). Russian teaching in China: History, reality and future. Russian language and literature studies, 3, 1-13.

Wang, S. R. (2016). Illustration on Keys of Guides on College English Teaching ,2015. Foreign Language World, $3,2-10$.

Wu, Q. D. (2004). Speech on video meeting of reforms of College English teaching delivered by (then) Deputy Minister of MOE, Wu, Qidi. Retrieved from http://www.moe.edu.cn/publicfiles/business/htmlfiles/moe/moe_176/200412/4915.html

Yang, H. Z. (2003). Review on 15 years of national CET4 and 6 in China. Journal of Foreign Langauge, 2003(3), 21-29.

Yu, J. J., \& Zhang, Y. L. (2019, Feb. 26). 38, 33 million learners recruited in Chinese higher education institution in 2018. Retrieved from http://www.xinhuanet.com/politics/2019-02/26/c_1124165826.htm

Notes

Note 1. National Foreign Language Teaching Advisory Board in Tertiary Education —NFLTATE under MOE is an subdivision of National Teaching Advisory Board In Tertiary Education under MOE, dedicating for issues around foreign language teaching in tertiary education.

Note 2. Shanghai Foreign Language Education Press was founded in 1979, under leadership of MOE, and operated by Shanghai International Studies University. It's the largest and the top press for foreign languages.

Note 3. Foreign Language Teaching and Research Press (FLTRP) is the largest university press for foreign languages.

Note 4. The Foreign Language Teaching and Research Association in Tertiary Education (brief as FLT RA) is an a social organization initiated by influential linguistics and educators working on CE, supporting the FLT Advisory Board with advising in classroom teaching particularly.

Note 5. 'FLTRP Cup' National English Speaking Contest was originated and co-organized by China Central Television (CCTV) and Foreign Language Teaching and Research Press (FLTRP). CCTV is a state television. It has 45 TV channels altogether, rating No.1 in the world, with most populous audience at home.

Note 6. Teaching Quality and Teaching Reform Program in Tertiary Education was launched by MOE.

Note 7. National Development and Reform Commission is an executive department of the State Council. 
Note 8. China Scholarship Council is a non-profit organization under MOE, financially support Chinese learning abroad.

\section{Copyrights}

Copyright for this article is retained by the author(s), with first publication rights granted to the journal.

This is an open-access article distributed under the terms and conditions of the Creative Commons Attribution license (http://creativecommons.org/licenses/by/4.0/). 